\title{
Parent Involvement in School Conceptualizing Multiple Dimensions and Their Relations with Family and Demographic Risk Factors
}

\author{
Gwynne O. Kohl, Liliana J. Lengua, \\ and Robert J. McMahon \\ University of Washington
}

\section{Conduct Problems Prevention Research Group ${ }^{1}$}

\begin{abstract}
Parent involvement (PI) in school is associated with more positive academic performance and social competence in children. However, there are inadequacies in current measures of PI and a need for a better understanding of predictors of PI. In this study, measures were obtained from a normative sample of 387 children in kindergarten and first grade from high-risk neighborhoods in 4 different sites. First, a confirmatory factor analysis of a theoretical factor model of PI identified 6 reliable multiple-reporter PI factors: Parent-Teacher Contact, Parent Involvement at School, Quality of Parent-Teacher Relationship, Teacher's Perception of the Parent, Parent Involvement at Home, and Parent Endorsement of School. Next, the relations among 3 specific family and demographic risk factors-parental education level, maternal depression, and single-parent status-and these 6 PI factors were examined using path analyses in structural equation modeling. Results indicated that the 3 risk factors were differentially associated with the 6 PI factors: Parental education was significantly associated with 4 PI outcomes, maternal depression was significantly associated with 5 PI outcomes, and single-parent status was significantly associated with 3 PI outcomes. No significant ethnic group differences between African American and Caucasian families were found in these relations. (C) 2000 Society for the Study of School Psychology. Published by Elsevier Science Ltd
\end{abstract}

Keywords: Parent-school relationship, Single parents, Depression, Parent educational background, Racial and ethnic differences.

Parent involvement (PI) in school is a topic of great interest for researchers and practitioners. At this point, there is substantial evidence that PI is asso-

Received May 6, 1999; accepted February 1, 2000.

Address correspondence and reprint requests to Liliana Lengua, University of Washington, Department of Psychology, Box 351525, Seattle, WA 98195-1525. Phone: 206-543-5655; fax: 206-685-3157; E-mail: liliana@u.washington.edu

${ }^{1}$ Members of the Conduct Problems Prevention Research Group, in alphabetical order, include Karen Bierman (Pennsylvania State University), John D. Coie (Duke University), Kenneth A. Dodge (Duke University), Mark T. Greenberg (Pennsylvania State University), John E. Lochman (University of Alabama), Robert J. McMahon (University of Washington), and Ellen E. Pinderhughes (Vanderbilt University). 
ciated with children's academic performance (e.g., Comer, 1988; Epstein, 1991; Reynolds, 1992) and social competence (Henderson, 1987; Kohl, Weissberg, Reynolds, \& Kasprow, 1994; Reynolds, Weissberg, \& Kasprow, 1992), and policymakers recognized the importance of involving parents in schools by incorporating federal legislation into the Goals 2000 Educate America Act (U.S. Department of Education, 1994). Given the importance of PI, identifying and understanding the variables impacting it is essential in developing interventions to enhance PI. Many family and demographic factors such as ethnicity, family composition, income, education level, and work status are associated with PI (see review, Eccles \& Harold, 1996). When these variables are immutable, as in the case of many sociodemographic variables, their identification is useful in determining specific groups at risk for low levels of PI. With proper identification, interventions can target these at-risk populations with more outreach and added support. The goal of this study was to examine the relations between a circumscribed set of family and demographic risk factors and PI. Prior to examining these relations, we conceptualized PI along six dimensions and empirically validated this model.

\section{FAMILY AND DEMOGRAPHIC RISK FACTORS AND PARENT INVOLVEMENT IN SCHOOL}

Although many family and demographic variables are associated with PI, three were selected for this study - parental education level, single-parent status, and maternal depression-for the reasons enumerated below. In addition, ethnicity, another variable associated with PI, was examined as a moderator.

Several lines of evidence converge to suggest the importance of including parental education in this study. In one of the few studies that has directly examined the relation between parental education and PI, Dauber and Epstein (1989) found that better educated parents are more involved at school and at home. The U.S. Department of Education (1996) found that parents with higher levels of education report less satisfaction with school practices than parents with lower levels of education, suggesting that more highly educated parents feel more comfortable criticizing the school. Grolnick, Benjet, Kurowski, and Apostoleris (1997) found that parents who see themselves as teachers and feel effective in helping their children in school are more likely to be involved. Parents' view of their role as teacher and their comfort level communicating with teachers and helping their children with school work may, in part, be a result of their own educational experience. A number of studies suggest that socioeconomic status (SES), of which parental education is a component, is a risk factor for PI. Using teacher report, Kohl et al. (1994) and Reynolds et al. (1992) found less 
involvement by families with high mobility, low SES, and minority status. Alexander and Entwisle (1996) showed that a disparity in school readiness (e.g., cognitive skills, behavioral expectations, and investment in school) exists between children from low- versus high-SES families as early as first grade. The gap in achievement between these two groups continues to widen as the years progress. Although most studies of SES combine income, occupation, and educational level, there is increasing recognition of the need to investigate these factors separately (e.g., Greenberg, Lengua, Coie, Pinderhughes, \& Conduct Problems Prevention Research Group, 1999). In the present study, parental education was examined alone to determine its specific role as a risk factor for PI.

The second risk factor included in this study was single-parent status. In several studies, teachers reported lower levels of school involvement for single parents (Epstein, 1984; Kohl et al., 1994; Reynolds et al., 1992). With the increasing number of single parents, this risk factor is important to study in the context of family-school relations. Children of single parents have more academic and behavior problems than do those of intact twoparent families (Zill, 1996). Single parents naturally have fewer resources such as money, social support, and time to invest in their child's education and development. Therefore, single-parent status is a marker of multiple risks that may influence a parent's likelihood of being involved in school or with the child directly.

The third risk factor included in this study, maternal depression, has not been previously studied in relation to PI in school. However, much research suggests that maternal depression is a risk factor for many child problems including both internalizing and externalizing behavior (e.g., Cummings \& Davies, 1994; Downey \& Coyne, 1990; Dumas \& Serketich, 1994) and social and academic competence (e.g., Downey \& Coyne, 1990). Along with the direct effects of maternal depression on children's academic success, PI in school may be a mediating factor between maternal depression and children's academic success. Depressed mothers often view their parenting roles less positively and may have less energy, motivation, and confidence to be involved either with their children directly or with school personnel (see review, Downey \& Coyne, 1990). In addition, because depressed individuals have been shown to elicit negative responses from others (Coyne, 1976), depressed mothers might have more trouble developing positive relationships with teachers.

The final risk factor included in this study, ethnic or racial minority status, is related to lower levels of PI. Kohl et al. (1994) found that minority status was associated with a decrease in the amount and quality of PI by teacher report. Moles (1993) wrote of "disadvantaged parents"-those with low income and minority status-having less involvement in school by teacher report. Lynch and Stein (1987) reported that Hispanic and African American parents offered fewer suggestions at special education meetings 
and knew significantly less about their children's special services than did Caucasian parents. Although minority status has been identified as a risk factor for PI, little research has examined the different pattern of relations among other family and demographic risk factors and PI within the context of separate minority groups. Eccles and Harold (1996) and Bierman (1996) suggested that understanding the relations between risk factors and PI within the context of a given ethnic group may sharpen the focus of interventions. Identifying risk factors and dimensions of PI that are relevant for specific ethnic or racial groups facilitates the development of culturally sensitive interventions. Therefore, instead of viewing minority status as a risk factor in this study, we chose to examine ethnicity as a moderator of the relations between family and demographic variables and PI.

\section{DIMENSIONS OF PARENT INVOLVEMENT IN SCHOOL}

To examine the relations between risk factors and PI, one must first adequately define and measure PI. PI has been defined and measured inconsistently across studies depending on the needs and limitations of individual studies. No consensus with regard to the relevant dimensions and the specificity of the dimensions to be assessed has been achieved. PI clearly is a complex construct encompassing many behaviors and attitudes. For this reason, it is important to examine the relations among these family and demographic factors and multiple specific components of PI. For example, a single mother may have low levels of attendance at school activities because of her work schedule and other childcare responsibilities, but consistently assist her child with homework in the evenings. Similarly, a less educated parent may feel comfortable attending school activities, but be unable to help her child with homework. A risk factor such as maternal depression may lead to less PI across all domains because of its negative effects on interpersonal relationships, worldview, and activity level. Therefore, one goal of this study was to determine how certain family and demographic risk factors are differentially associated with various types of PI.

We developed a multidimensional model of PI by examining the strengths and weaknesses of several current models (Eccles \& Harold, 1996; Epstein, 1995; Grolnick \& Slowiaczek, 1994). Grolnick and Slowiaczek (1994) conceptualized three dimensions of parents' school involvement: (a) behavior (participation in school activities and helping with school work at home); (b) cognitive-intellectual (exposing the child to intellectually stimulating activities); and (c) personal (staying informed about the child's schooling). One concern with this model is that the dimensions are broad, combining various specific types of involvement into each dimension. For example, the behavior domain combines parent activities in the 
school environment with activities in the home environment. Broad categories such as these may mask associations with specific risk factors and child outcomes.

Eccles and colleagues (see review in Eccles \& Harold, 1996) delineated five dimensions of parent-initiated involvement in their Michigan Childhood and Beyond Study: (a) monitoring (how parents respond to the teacher's requests for helping their children with school work such as checking homework or listening to them read); (b) volunteering (parents' level of participation in activities at school including Parent-Teacher Organization [PTO]); (c) involvement (parents' involvement in their children's daily activities related to homework); (d) contacting the school about their children's progress; and (e) contacting the school to find out how to give extra help. The dimentsions monitoring and involvement appear to be two behaviors related to directly helping the child with homework, and may, therefore, be better conceptualized as one construct. The last two dimensions both involve contacting the school; in addition, these two were each measured by only one item and, therefore, the reliability of these dimensions cannot be determined.

Epstein (1995) outlined six dimensions of parent-school partnerships that focus on the school's role in fostering these relationships. Her six dimensions are: (a) parenting (helping families provide home-based support for learning); (b) communicating (designing effective school-home communication about school programs and progress); (c) volunteering (recruiting and organizing parents to support school goals and child development); (d) learning at home (providing information to families to help students at home with homework); (e) decision making (including parents in school decisions, developing parent leaders and representatives); and (f) collaborating with the community (integrating community resources and services to strengthen school programs, family practices, and student development). These dimensions are well-defined and provide useful guidelines for formulating corresponding dimensions of parent behaviors. However, they measure teacher and school-initiated behaviors rather than parent-initiated involvement.

The three models differ in the scope, number, and reliability of dimensions assessed. Creating dimensions of PI that are specific in behavioral scope, capture the variety of PI behaviors, and consist of enough content items to reliably measure the construct will improve the likelihood that the findings are useful in future research. The dimensions in the Grolnick and Slowiaczek (1994) model are very broad, encompassing many different behaviors within a given factor, whereas the dimensions in Eccles and colleagues' model (Eccles \& Harold, 1996) are quite narrowly defined, creating different dimensions from apparently similar behaviors. Of the three models, the Epstein (1995) model creates the most behaviorally defined nonoverlapping factors. Grolnick and Slowiaczek (1994) as well as others 
(e.g., Griffith, 1996; Seefeldt, Denton, Galper, \& Younoszai, 1998; Watkins, 1997) measure a limited number of dimensions of PI. Eccles and Harold (1996) and others (e.g., Hoover-Dempsey, Bassler, \& Brissie, 1992) used single-item assessments for a particular dimension. In our model, we measure six specific facets of PI using multiple-item assessment for each dimension.

The three models also differ in the number of reporters used to assess PI. Grolnick and colleagues' model (Grolnick \& Slowiaczek, 1994; Grolnick et al., 1997) is the only model that relied on multiple-reporter ratings. Most studies rely on single-reporter ratings with unknown reporter biases (e.g., Griffith, 1996; Kohl et al., 1994; Seefeldt et al., 1998). Epstein (1984, 1996) found that parent and teacher reports differ significantly; teachers reported lower levels of PI for single parents than married parents, whereas single parents consistently reported more involvement at home. In our study, we used ratings by both parents and teachers when applicable for a more valid assessment.

A valid conceptualization of PI must account for the distinction between parent- and teacher-initiated PI. Differentiating between parent- or schoolinitiated PI may help explain some of the contradictory research findings that have associated PI with both positive and negative outcomes. For example, Epstein (1996) found that teachers initiated more contact when children were doing poorly in school, whereas parents initiated more contact if their children were doing well. Eccles and Harold (1996) and Grolnick and Slowiaczek (1994) both focused on parent-initiated PI, whereas Epstein focused on school-initiated PI. In our study, we focused on parent-initiated contact to isolate risk factors for parent behaviors.

The quality of the involvement is another important component of PI. Kohl and colleagues (1994) found the quality of the relationship to be more strongly associated with child outcomes than the amount of parentteacher contact. Interestingly, none of these models accounted for parent or teacher perceptions of the quality of involvement. In our model, we include three dimensions aimed at measuring the quality of PI: the quality of the relationship between parent and teacher, the teacher's perception of the parent's value of education, and the parent's satisfaction with the child's school.

Three dimensions of PI were common to the three models outlined: parent-teacher contact to facilitate monitoring their children's school progress and helping their children with homework, parent involvement in school activities, and parent involvement directly with their child at home to facilitate intellectual stimulation and school success. Therefore, in conjunction with the three quality-related dimensions reviewed above, these three common dimensions were chosen as factors for the current model.

The current study contributes by using a multidimensional conceptualization of PI that is based on a theoretical model, using multiple-reporter 
ratings where appropriate, and employing a sample that represents a range of children and families in four regionally-diverse high-risk communities. This approach is used to examine the relations between family and demographic risk and PI using path analyses. The relations between risk factors and PI were then re-examined separately for African American and Caucasian families.

\section{METHOD}

\section{Participants}

The participants in this study were parents, children, and teachers who were part of a larger longitudinal multisite investigation of the development and prevention of conduct problems in children. Details of this investigation are described elsewhere (Conduct Problems Prevention Research Group, 1992). Participants were selected from four areas of the country, each representing a different cross-section of the American population: (a) Durham, NC, a small city with a large low- to middle-SES single- and twoparent African American population in the urban public schools; (b) Nashville, TN, a moderate-sized city with a mix of low- to middle-SES single- and two-parent African American and Caucasian families; (c) Seattle, WA, a moderate-sized city with a low- to middle-SES ethnically diverse population including Caucasians, African Americans, Asian and Pacific Islanders, Chicano/Latinos, and Native Americans; (d) central Pennsylvania, a mostly rural area with low- to middle-SES two-parent Caucasian families. Schools were identified at each of the four sites based on measures of poverty and low parental education levels that were characteristic of the parents of children in the schools, and on location of the schools' "catchment areas" in high-crime areas (Lochman \& Conduct Problems Prevention Research Group, 1995).

As part of the larger intervention study design, schools were randomly assigned to intervention and comparison groups. A normative sample of children was then selected from the comparison schools and was used for the analyses in this study. From these schools, 100 kindergarten children were selected at each site ( 87 in Seattle) on the basis of their race, gender, and level of teacher-reported behavior problems. The normative sample of 100 children from each site was selected by including 10 children at each decile of the distribution of scores on a teacher-report screen for behavior problems, which consisted of items from the Teacher Observation of Child Adaptation-Revised (Werthamer-Larsson, Kellam, \& Wheeler, 1991). The original sample consisted of 387 subjects; however, 2 subjects were removed from the data because their primary caregivers were male. Due to missing data, the number of subjects included in the present analyses ranged from 331 to 347 , depending on the specific analyses. A smaller subset of subjects 
was selected for analyses exploring the ethnic differences between African American $(n=69)$ and Caucasian $(n=77)$ participants for reasons discussed below.

Across all sites, the mean age of the children in the first year of this study was 6.36 years $(S D=0.44)$, and the sample was $50 \%$ male, with $49 \%$ of the sample from an ethnic minority background (42\% African American and $7 \%$ other). Eighty-six percent of the Durham sample, $50 \%$ of the Nashville sample, $1 \%$ of the Pennsylvania sample, and $58 \%$ of the Seattle sample was ethnic minority. Forty-one percent of the sample (59\% in Durham, $56 \%$ in Nashville, $12 \%$ in Pennsylvania, 36\% in Seattle) were single parents. Ninetyfour percent of the primary custodial parents were biological mothers; the remaining $6 \%$ were adoptive, foster, or step-mothers, or other relatives. The modal Hollingshead SES indicator was 5 ( 5 in Durham, 5 in Nashville, 5 in Pennsylvania, 3 in Seattle), with 5 representing the lowest level of SES. Four percent of the sample had a Hollingshead SES index of 1, 16\% had an index of 2, 19\% had an index of 3, 29\% had an index of 4, and $32 \%$ had an index of 5 .

\section{Procedures}

Parent report of sociodemographic information and the risk factors enumerated below was collected in home interviews in the summer prior to the child entering first grade. To minimize the effects of parents' previous experience with their children's schools, parent report of PI was collected in the summer following first grade during home interviews with the primary custodial parent. Teacher report of PI was obtained in teacher interviews in the spring of the children's first-grade year. Although parent- and teacherreport were measured several months apart, they both measured PI during first grade.

\section{Measures}

Table 1 shows the sample sizes, means, standard deviations, and ranges for all of the following study variables.

Family and demographic variables. For education level, a standard $z$-score was created for the mean of both parents' number of years of schooling. If the family was headed by a single-parent, then that parent's level of education was used. The mean level for this sample was a high school diploma or GED.

For maternal depression, each female head of household completed the Center for Epidemiological Studies-Depression Scale (Radloff, 1977), designed to measure the major components of depressive symptomatology. 
Table 1

Means, Standard Deviations, and Ranges for Family and Demographic Variables and Parent Involvement Factors

\begin{tabular}{|c|c|c|c|c|c|}
\hline Variable & $n$ & $M$ & $S D$ & Minimum & Maximum \\
\hline \multicolumn{6}{|l|}{ Risk factors } \\
\hline $\begin{array}{l}\text { Mother's and father's education } \\
\text { levels (z-score) }\end{array}$ & 385 & 0.00 & 0.91 & -2.73 & 2.79 \\
\hline Maternal depression & 381 & 13.38 & 9.53 & 0.00 & 50.00 \\
\hline $\begin{array}{l}\text { Single-parent status }(0=\text { couple }, \\
\quad 1=\text { single })^{\mathrm{a}}\end{array}$ & 383 & & & & \\
\hline \multicolumn{6}{|l|}{ Parent involvement factors } \\
\hline Parent-Teacher Contact & 385 & 1.10 & 0.55 & 0.00 & 2.75 \\
\hline $\begin{array}{l}\text { Parent Involvement at School } \\
\text { Quality of Parent-Teacher }\end{array}$ & 385 & 1.13 & 0.70 & 0.00 & 3.50 \\
\hline Relationship & 385 & 2.61 & 0.89 & 0.00 & 4.00 \\
\hline Teacher's Perception of Parent & 374 & 2.27 & 1.18 & 0.00 & 4.00 \\
\hline Parent Involvement at Home & 361 & 2.34 & 0.85 & 0.00 & 4.00 \\
\hline Parent Endorsement of School & 361 & 3.20 & 0.81 & 0.00 & 4.00 \\
\hline
\end{tabular}

Note. Parent Involvement factor scores ranged from 0 to 4 , with 4 being the highest level of involvement. ${ }^{a}$ Because single-parent status is a dichotomous variable, descriptive statistics are not given. $42 \%$ of the sample were single parents.

For the complete 20-item scale, Radloff (1977) reported high internal consistency ( $\alpha$ ranging from .84 to .90 across three samples) and adequate discriminant validity, as assessed by comparing psychiatric inpatient and general population samples, and by levels of severity within patient groups. Respondents were asked to rate the frequency of each symptom on a 4 point response scale. A standard z-score was created for each mother's total scale score. The scale score was considered missing if $25 \%$ of the items on the scale was missing $(n=3)$.

For single-parent status, a dichotomous variable was created: Two-parent households were coded 0 and single-parent households were coded 1 . Households in which the parent was not married but had a live-in partner for at least 12 months were coded as two-parent households.

Parent involvement factors. The Parent-Teacher Involvement Questionnaire (PTIQ; Conduct Problems Prevention Research Group, 1995) was developed for the larger project. Its aim was to assess various facets of parentschool partnerships, and it has both parent- and teacher-report versions. The teacher report is a 21-item measure assessing (a) the amount, type, and initiator of contact that occurs between parents and teachers; (b) the quality of the relationship between parent and teacher; (c) the parent's involvement in the child's school; and (d) the teacher's perception of the parent's value of education. The responses are coded on a 5-point scale ranging from 0 to 4 . 
The parent-report version of the PTIQ is a similar 26-item measure assessing: (a) the amount, type, and initiator of contact that occurs between parents and teacher; (b) the quality of the relationship between parent and teacher; (c) the parent's involvement in the child's school; (d) the degree of academic stimulation at home; and (e) the parent's satisfaction with the child's school. These items are also coded on a 5-point scale ranging from 0 to 4 . Details of the factor analysis of this measure are presented in the next section.

Ethnicity. To look at patterns of ethnic group differences, race was coded 0 for Caucasian participants and 1 for African American participants. Because of very small sample sizes for Latino, Asian American, Native American, and other ethnic participants, they were excluded from ethnicity analyses.

\section{RESULTS}

\section{Overview}

First, results are presented from the confirmatory factor analysis testing the theoretical model of PI. Second, correlations among the risk factors and PI factors are examined. Third, path analyses are presented examining the relations among family and demographic risk, ethnicity, and PI factors.

\section{Dimensions of Parent Involvement}

A model of PI was tested with the following six factors: (a) Parent-Teacher Contact, (b) Parent Involvement at School, (c) Quality of Parent-Teacher Relationship, (d) Teacher's Perception of Parent's Value of Education (Teacher's Perception of Parent), (e) Parent Involvement at Home, and (f) Parent Endorsement of School. Each dimension is described briefly below.

First, the amount of contact parents initiated with teachers consisted of four parent-report items (e.g., "How often did you call the child's teacher in the past year?" and "How often did you attend parent-teacher conferences in the past year?") and four parallel teacher-report items asking the teacher to evaluate the parent's level of involvement.

Second, PI in school-related activities consisted of four parallel parentand teacher-report items such as "How often have you visited your child's school for special events?" and "How often have you attended PTO meetings in the last year?"

Third, the quality of the parent-teacher relationship comprised six parent-report items measuring the parent's feeling about the teacher (e.g., "Do you enjoy talking with your child's teacher?" and "Do you feel that the 
teacher cares about your child?") and five teacher-report items that reflected the teacher's perspective of the relationship (e.g., "Is the parent interested in knowing you?" and "Can you talk to the parent?").

Fourth, the teacher's perception of the parent's value of education consisted of three teacher-report items such as "Does the parent encourage positive attitudes toward education?" and "How important is education in this family?"

Fifth, PI at home in activities related to school readiness comprised three parent-report items such as "How often do you read to your child?" and "How often do you take your child to the library?"

Finally, parent endorsement of the school consisted of four parent-report items asking the parent if "the child's school is a good place for her child to be" and if "the school is preparing her child for the future."

To empirically assess the parent involvement factors, a confirmatory factor analysis (CFA) was conducted using the covariance matrix. Maximum likelihood estimation was used with listwise deletion of missing data. The results for this CFA indicated that the theoretical model provided an adequate fit to the data, $\chi^{2}(558, N=332)=1404.42, p<.0001$, Comparative Fit Index $=.89$, Non-Normed Fit Index $=.87$, Normed Fit Index $=.83$, Root Mean Square Error of Approximation $=.07$. A test of multivariate kurtosis, Mardia's coefficient, was 137.13 for this model, indicating potential distributional problems. However, there were negligible differences in the parameter estimates using regular versus scaled (robust) standard errors, suggesting that kurtosis was not resulting in a decrement in fit. When the fit of the model was considered satisfactory, composite scores for each factor were formed by averaging the items within each factor. The composite score for a given subject was considered missing if $25 \%$ of the items comprising the factor were missing. The possible range of scores for each factor is 0 to 4 .

As shown in Table 2, internal consistency (Cronbach's alpha) is as follows: Parent-Teacher Contact $(\alpha=.71)$, Parent Involvement at School $(\alpha=$ .81), Quality of Parent-Teacher Relationship $(\alpha=.89)$, Teacher's Perception of Parent $(\alpha=.93)$, Parent Involvement at Home $(\alpha=.67)$, and Parent Endorsement of School $(\alpha=.92)$. For the multiple-reporter factors, teacher-report items consistently loaded more strongly on the factors than did parent-report items. As shown in Table 3, correlations among the various factors ranged from $r=|.04|$ to $|.61|$. The largest correlations were between Parent-Teacher Contact and Parent Involvement in School $(r=.61)$ and Parent Involvement in School and Quality of Parent-Teacher Relationship $(r=.60)$. The smallest correlation was between Parent-Teacher Contact and Parent Endorsement of School $(r=.04)$. Overall, the correlations among the multiple-reporter factors were the highest, and the correlations between Parent Endorsement of School and the other five factors were the lowest. 
Table 2

Parent Involvement Factors

\begin{tabular}{|c|c|c|}
\hline Factor & $\begin{array}{l}\text { Cronbach } \\
\text { Alpha }\end{array}$ & $\begin{array}{l}\text { Item } \\
\text { Loading }\end{array}$ \\
\hline Parent-Teacher Contact & .71 & \\
\hline \multicolumn{3}{|l|}{ Parent report } \\
\hline Called child's teacher & & .13 \\
\hline Written child's teacher & & .18 \\
\hline Stopped to talk to teacher & & .58 \\
\hline Attended parent-teacher conference & & .14 \\
\hline \multicolumn{3}{|l|}{ Teacher report } \\
\hline Frequency parent called in the past year & & .55 \\
\hline Frequency parent has written in the past year & & .57 \\
\hline $\begin{array}{l}\text { Frequency parent has stopped by in the past } \\
\text { year }\end{array}$ & & .89 \\
\hline $\begin{array}{l}\text { Frequency parent has attended conferences } \\
\text { in the past year }\end{array}$ & & .49 \\
\hline Parent Involvement at School & .81 & \\
\hline \multicolumn{3}{|l|}{ Parent report } \\
\hline Visited school for special event & & .28 \\
\hline Attended PTO meetings & & .31 \\
\hline Send things to class (books, etc.) & & .24 \\
\hline Volunteer at child's school & & .54 \\
\hline \multicolumn{3}{|l|}{ Teacher report } \\
\hline $\begin{array}{l}\text { Frequency parent attended special events in } \\
\text { the past year }\end{array}$ & & .77 \\
\hline $\begin{array}{l}\text { Frequency parent attended PTO meetings in } \\
\text { the past year }\end{array}$ & & .68 \\
\hline Frequency parent sends things to class & & .77 \\
\hline Frequency parent volunteers at school & & .81 \\
\hline Quality of Parent-Teacher Relationship & .89 & \\
\hline \multicolumn{3}{|l|}{ Parent report } \\
\hline Enjoy talking with child's teacher & & .36 \\
\hline Feel teacher cares about my child & & .27 \\
\hline Feel teacher is interested in knowing me & & .28 \\
\hline $\begin{array}{l}\text { Feel comfortable talking with the teacher } \\
\text { about my child }\end{array}$ & & .28 \\
\hline Teacher pays attention to my suggestions & & .31 \\
\hline $\begin{array}{l}\text { Ask teacher questions/suggestions about my } \\
\text { child }\end{array}$ & & .24 \\
\hline \multicolumn{3}{|l|}{ Teacher report } \\
\hline $\begin{array}{l}\text { Is the parent interested in knowing the } \\
\text { teacher? }\end{array}$ & & .77 \\
\hline Can the teacher talk to the parent? & & .75 \\
\hline $\begin{array}{l}\text { Is the teacher comfortable talking about the } \\
\text { child's problems? }\end{array}$ & & .52 \\
\hline Frequency parent makes suggestions? & & .67 \\
\hline $\begin{array}{l}\text { Does the parent have the same goals for the } \\
\text { child? }\end{array}$ & & .93 \\
\hline
\end{tabular}


Table 2

Continued

\begin{tabular}{|c|c|c|}
\hline Factor & $\begin{array}{c}\text { Cronbach } \\
\text { Alpha }\end{array}$ & $\begin{array}{c}\text { Item } \\
\text { Loading }\end{array}$ \\
\hline Teacher's Perceptions of Parent & .93 & \\
\hline \multicolumn{3}{|l|}{ Teacher report } \\
\hline \multicolumn{3}{|l|}{ Does parent encourage positive attitudes } \\
\hline Is parent involved in school life? & & $\begin{array}{r}.71 \\
.92\end{array}$ \\
\hline How important is education in this family? & & .92 \\
\hline Parent Involvement at Home & .67 & \\
\hline \multicolumn{3}{|l|}{ Parent report } \\
\hline Do you read to you child? & & .66 \\
\hline Do you take your child to the library? & & .70 \\
\hline \multicolumn{3}{|l|}{ Do you play games related to learning at home } \\
\hline with your child? & & .47 \\
\hline Parent Endorsement of School & .92 & \\
\hline \multicolumn{3}{|l|}{ Parent report } \\
\hline Child's school is a good place for my child & & .84 \\
\hline School staff is doing good things for my child & & .95 \\
\hline I have confidence in the people at school & & .89 \\
\hline School is preparing my child for the future & & .79 \\
\hline
\end{tabular}

Note. Standardized coefficients are given.

\section{Family and Demographic Risk Factors as Predictors of Parent Involvement}

Exploratory path analyses were conducted using LISREL to simultaneously test the relations of each predictor variable with the outcome variables

Table 3

Correlations Among Family and Demographic Variables and Parent Involvement Factors

\begin{tabular}{|c|c|c|c|c|c|c|c|c|c|}
\hline Variable & 1 & 2 & 3 & 4 & 5 & 6 & 7 & 8 & 9 \\
\hline 1. Parent education & 1.00 & & & & & & & & \\
\hline 2. Maternal depression & .27 & 1.00 & & & & & & & \\
\hline 3. Single parent & .13 & .26 & 1.00 & & & & & & \\
\hline $\begin{array}{l}\text { 4. Parent-Teacher Contact } \\
\text { 5. Parent Involvement at }\end{array}$ & -.14 & -.13 & -.05 & 1.00 & & & & & \\
\hline $\begin{array}{l}\text { 5. Parent Involvement at } \\
\text { School }\end{array}$ & -.23 & -.29 & -.18 & .61 & 1.00 & & & & \\
\hline 6. Quality of Parent-Teacher & & & & & & & & & \\
\hline Relationship & -.09 & -.17 & -.12 & .51 & .60 & 1.00 & & & \\
\hline $\begin{array}{l}\text { 7. Teacher's Perception of } \\
\text { Parent }\end{array}$ & -.27 & -.39 & -.25 & .35 & .56 & .57 & 1.00 & & \\
\hline 8. Parent Involvement at & & & & & & & & & \\
\hline Home & -.23 & -.28 & -.10 & .39 & .51 & .37 & .35 & 1.00 & \\
\hline $\begin{array}{l}\text { 9. Parent Endorsement of } \\
\text { School }\end{array}$ & .03 & -.11 & -.01 & .04 & .21 & .45 & .17 & .26 & 1.00 \\
\hline
\end{tabular}

Note. Coefficients of .11 and above in absolute value are significant at the .01 level (two-tailed test). 


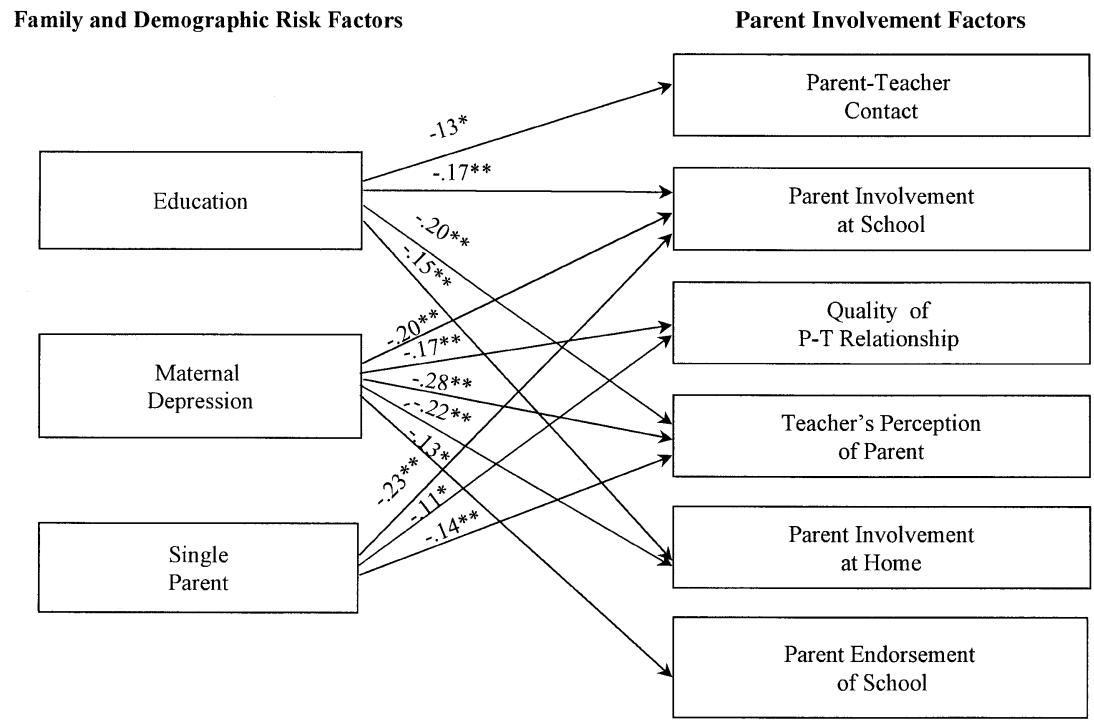

Figure 1. Model for whole sample illustrating differential pattern of prediction between family and demographic risk factors and parent involvement factors $(n=347)$. Standardized beta values and their significance levels are given; $* p<.05, * * p<.01$.

while controlling for the other predictors and accounting for the correlations among the outcome variables. Covariance matrices were analyzed using maximum likelihood estimation and listwise deletion of missing data. The first model tested was the full model comprising the entire sample (due to missing data, the effective sample size was 347 participants). In this model, the relations between each risk factor (parental education, maternal depression, and single-parent status) and the six PI outcome factors (Parent-Teacher Contact, Parent Involvement at School, Quality of Parent-Teacher Relationship, Teacher's Perception of Parent, Parent Involvement at Home, and Parent Endorsement of School) were estimated. Because all paths were estimated in these analyses including the correlations among the exogenous variables (risk factors) and those among the endogenous variables (PI outcomes), the model was saturated. Therefore, goodness-of-fit indices were not available.

As shown in Figure 1, the full model had many significant paths. For this model, parental education was significantly associated with four PI outcomes: Parent-Teacher Contact $(\beta=-.13, z=-2.32, p<.05)$, Parent Involvement at School $(\beta=-.17, z=-3.30, p<.01)$, Teacher's Perception of Parent $(\beta=-.20, z=-4.06, p<.01)$, and Parent Involvement at Home $(\beta=-.15, z=-2.81, p<.01)$. Maternal depression was significantly associated with five PI outcomes: Parent Involvement at School $(\beta=$ 
$-.20, z=-3.79, p<.01)$, Quality of Parent-Teacher Relationship $(\beta=$ $-.17, z=-3.06, p<.01)$, Teacher's Perception of Parent $(\beta=-.28$, $z=-5.46, p<.01)$, Parent Involvement at Home $(\beta=-.22, z=-3.91$, $p<.01)$, and Parent Endorsement of School $(\beta=-.13, z=-2.24, p<$ $.05)$. Single-parent status was significantly associated with three PI outcomes: Parent Involvement at School $(\beta=-.23, z=-4.49, p<.01)$, Quality of Parent-Teacher Relationship $(\beta=-.11, z=-2.03, p<.05)$, and Teacher's Perception of Parent $(\beta=-.14, z=-2.64, p<.01)$.

\section{Pattern of Ethnic Group Differences Among Family and Demographic Risk-Parent Involvement Relations}

Due to a site $\times$ ethnicity confound in this sample (two of the sites are ethnically homogenous, one being 99\% Caucasian [Central Pennsylvania] and rural and one being 86\% African American and urban [Durham, NC]), only the ethnically heterogeneous sites were used for the following analyses. Therefore, the effective sample sizes for the path analyses were reduced to 69 African American participants and 77 Caucasian participants.

Before examining the path analyses within ethnic groups, group differences for the factors included in the models were explored. As shown in Table 4, African Americans had significantly higher levels of risk for two of the risk factors and a trend toward significance for the third. They had a significantly lower mean level of education, $t(144)=-2.14, p<.05$; a significantly higher percentage of single parents, $74 \%$ for African Americans as opposed to $27 \%$ for Caucasians, $\chi^{2}(1, n=170)=35.81, p<.001$; and a higher, though nonsignificant, mean level of maternal depression, $t(144)=$ $-1.89, p=.06$. African Americans also had lower levels of involvement for all four factors that contain teacher-report items-Parent-Teacher Contact, $t(144)=2.48, p=.01$; Parent Involvement at School, $t(144)=4.14$, $p<.01$; Quality of Parent-Teacher Relationship, $t(144)=2.10, p<.05$; and Teacher's Perception of Parent, $t(144)=4.39, p<.01$; - but no differences in involvement for the two factors based solely on parent self-report.

Possible differences across ethnicity in the path model described above were explored by testing cross-group (African American and Caucasian) path models in LISREL. First, the path coefficients in the model for African Americans were constrained to equal those in the model for Caucasians. Next, the paths were freed to vary across the groups. A chi-square difference test between the chi-square for the constrained model and that of the unconstrained model provided a statistical test indicating whether the set of paths differed across groups overall. Again, all paths were estimated in these analyses, including the correlations among the risk factors and those among the PI factors, resulting in saturated models. Thus, no goodness-offit indices were available. 
Table 4

Mean Differences by Ethnicity for Family and Demographic Variables and Parent Involvement Factors

\begin{tabular}{|c|c|c|c|c|c|c|}
\hline \multirow[b]{2}{*}{ Variable } & \multicolumn{2}{|c|}{ Caucasian } & \multicolumn{2}{|c|}{$\begin{array}{l}\text { African } \\
\text { American }\end{array}$} & \multirow[b]{2}{*}{$t$} & \multirow[b]{2}{*}{$p$} \\
\hline & $M$ & $S D$ & $M$ & $S D$ & & \\
\hline \multicolumn{7}{|l|}{ Risk factors } \\
\hline $\begin{array}{l}\text { Mother's and father's } \\
\text { education }\end{array}$ & 0.05 & 0.92 & 0.35 & 0.78 & -2.14 & .03 \\
\hline Maternal depression & 14.50 & 11.06 & 17.80 & 9.97 & -1.89 & .06 \\
\hline $\begin{array}{l}\text { Single-parent status } \\
\quad(0=\text { couple, } 1=\text { single })^{\mathrm{a}}\end{array}$ & & & & & & .00 \\
\hline \multicolumn{7}{|l|}{ Parent involvement factors } \\
\hline $\begin{array}{l}\text { Parent-Teacher Contact } \\
\text { Parent Involvement at }\end{array}$ & 1.24 & .51 & .03 & 0.53 & 2.48 & .01 \\
\hline School & 1.29 & 0.75 & 0.83 & 0.59 & 4.14 & .00 \\
\hline $\begin{array}{l}\text { Quality of Parent-Teacher } \\
\text { Relationship }\end{array}$ & 2.72 & 0.78 & 2.44 & 0.85 & 2.11 & .04 \\
\hline $\begin{array}{l}\text { Teacher's Perception of } \\
\text { Parent }\end{array}$ & 2.41 & 1.12 & 1.60 & 1.11 & 4.39 & .00 \\
\hline $\begin{array}{l}\text { Parent Involvement } \\
\text { at Home }\end{array}$ & 2.19 & 0.81 & 2.07 & 0.85 & 0.91 & .37 \\
\hline $\begin{array}{l}\text { Parent Endorsement of } \\
\text { School }\end{array}$ & 3.15 & 0.92 & 3.01 & 0.83 & 1.01 & .32 \\
\hline
\end{tabular}

Note. Sample size for the Caucasian group was 77. Sample size for the African American group was 69. Parent Involvement Factor scores ranged from 0 to 4 , with 4 being the highest level of involvement.

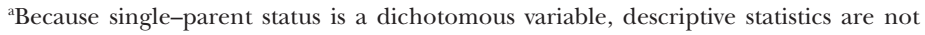
given. 27\% of Caucasian parents and $74 \%$ of African American parents were single parents. Group differences were analyzed using a chi-square difference test $\chi^{2}(1, N=$ 170) $=35.81, p>.001$.

The overall difference in the pattern of relations for African American versus Caucasian families was not significant, $\chi^{2}$ difference $(18)=20.15, p=$ .32 , suggesting that patterns between the various risk factors and the PI dimensions were comparable for African American and Caucasian families. ${ }^{2}$

\section{DISCUSSION}

This study found different patterns of relations between the three risk factors studied-parental education, maternal depression, and single-parent status-and the six PI dimensions. Furthermore, these patterns were not

\footnotetext{
${ }^{2}$ However, there were some large differences between the two ethnic groups in the magnitude of certain path coefficients (i.e., standardized path coefficient differences of a magnitude of at least $|.30|$ ). Whereas for Caucasian parents, education level was significantly associated with both Parent Involvement at School $(\beta=-.36, z=-3.20, p<.01)$ and Parent Involvement at Home $(\beta=-.32, z=-2.76, p<.01)$, this was not the case for African American parents (Parent Involvement at School: $\beta=-.06, z=-0.51, p=.30$; Parent Involvement at Home: $\beta=-.02, z=-0.14, p=.44)$.
} 
significantly different for Caucasian and African American families. This study also made a number of methodological advances over earlier studies in its conceptualization of PI: It used CFA to test a theoretical multidimensional model, used multiple-reporter ratings where appropriate, and sampled children and families from regionally diverse high-risk communities. Before discussing the relations between risk factors and PI, a brief review of the six PI dimensions is presented.

The first type of involvement was the amount of direct contact with the teacher either in person, by phone, or by written document. This type of involvement is important because it should facilitate parents' knowledge of their children's school progress as well as general school practices, rules, expectations, and programs. The second dimension was PI at school including volunteering, PTO events, and attending events. This dimension allows parents to model the importance of school by being present for activities. The third dimension was the level of PI at home in school- and learning-related activities. This type of involvement is important because it includes activities such as helping with homework, reading to children, and involving them in other educational activities that will supplement and enhance their school-based learning.

The next three dimensions assessed both parent and teacher attitudes and perceptions related to PI. The fourth was the quality of the parentteacher relationship. Creating a relationship in which both parent and teacher feel they are working toward the same goals and can speak openly and honestly should benefit the child's progress. In fact, Kohl et al. (1994) found that the quality of the parent-teacher relationship was more strongly associated with positive child outcomes than was the amount of involvement. The fifth dimension was the teacher's perception of the parent's value of education. Because the teacher does not directly observe the parent-child interactions at home, $\mathrm{s} /$ he cannot accurately verify parent report of the level of home involvement. Therefore, this dimension is a more general measure based on the teacher's assessment of the parent's investment in the child's education. The last dimension was the parents' endorsement of the school. This dimension assesses the parents' feelings about the school in general. Lareau (1996) and the U.S. Department of Education (1996) found that parents' expectations and criticisms of school vary by sociodemographic characteristics such as income and education level.

One must consider the possibility that some of these dimensions of PI are causally related. For instance, the quality of the parent-teacher relationship might influence the parent's level of school involvement and his or her endorsement of the school in general. Several PI interventions have provided support for this hypothesis, demonstrating that when teachers reach out to parents and improve communication with them, parents become more involved in school in a variety of ways (e.g., Comer, 1988; Epstein, 1991). Conversely, the parent's level of involvement may influence the 
teacher's perception of the parent and, in turn, influence the quality of the parent-teacher relationship. Parents' perception of the school, as measured by their endorsement of it, may influence their willingness to be involved. Seefeldt et al. (1998) noted a relationship between parents' view of school climate and school-related PI for former Head Start parents. Conversely, Haynes, Comer, and Hamilton-Lee (1989) noted that increasing PI in school was related to improved parental perceptions of the school. The specific nature of these relationships was not investigated in this study. Nonetheless, this model of PI allows for the assessment of multiple, conceptually distinct, yet empirically related aspects of PI that can facilitate future understanding of the types of PI that predict positive child outcomes.

All three of the risk factors-parental education, maternal depression, and single-parent status-were significantly and differentially related to dimensions of PI. First, parental education was related to parent-teacher contact, PI in school, the teacher's perception of the parent's value of education, and PI at home. These findings suggest that low parental education is associated with lower levels of active involvement in many domains, but not related to the quality of the parent-teacher relationship or the parent's endorsement of the school. Perhaps being better educated facilitates parent awareness of the importance of directly supporting their children's education. Additionally, less educated parents may have had life (and school) experiences causing them to feel less able to be actively involved in their child's school. They may feel that they do not have the necessary skills to help their children or that they should not interfere with the school's authority. Leitch and Tangri (1988) noted that disadvantaged families may feel that teachers, who they perceive as more educated, are looking down on them. Kellaghan, Sloane, Alvarez, and Bloom (1993) noted that the closer home and school environments resemble one another, the easier it is for children and parents to transition between the two.

Second, maternal depression was related to PI at school, the quality of the parent-teacher relationship, the teacher's perception of the parent's value of education, PI at home, and parent endorsement of school. These results suggest that depressed mothers are less likely to demonstrate PI in almost every domain except direct parent-teacher contact. A depressed mother may be able to muster the energy to contact her child's teacher if there is a problem. However, she may lack the motivation and extra energy needed to be involved in school or home activities with her child. This lack of involvement may, in turn, adversely affect the teacher's perception of the parent and their relationship. In addition, the interpersonal difficulties that are often associated with depression (Coyne, 1976) may further hinder her relationship with the teacher. Depressed mothers generally feel more negatively about their lives (Downey \& Coyne, 1990). These negative feelings could be directed at the school, the teacher, and the child, decreasing 
both her likelihood of initiating any involvement and her positive perception of others.

Third, single-parent status was related to PI at school, the quality of the parent-teacher relationship, and the teacher's perception of the parent's value of education. This risk factor was associated with the fewest number of PI factors. Single-parent status was not related to the amount of parentteacher contact. In addition, single parents did not report lower levels of involvement with their children at home or endorsement of the school. Because single parents have fewer resources in terms of child care and free time and are, therefore, less likely to be involved at school, teachers may be more likely to perceive these parents as less involved and invested in their children's education. However, single parents do report being just as involved as dual-parent families with their children at home (Epstein, 1984). Additionally, due to their limited resources and the need to focus on their top priorities, they may view having direct contact with their children's teachers as more important than being involved in school activities. Overall, each of the PI factors was associated with at least one of the risk factors. The different pattern of relations between family and demographic risk factors and PI suggests that these factors are assessing somewhat different and unique aspects of PI. It also suggests that such demographic variables must be taken into account in efforts to increase PI.

Past research conceptualizing minority status as a risk factor has shown that African American parents have lower levels of involvement in school (Kohl et al., 1994; Moles, 1993; Reynolds et al., 1992). In this study, we used a different approach, exploring whether the pattern of associations between family and demographic risk factors and PI differed by ethnic group (African Americans vs. Caucasians). No significant differences emerged in the overall patterns of relations among risk and PI factors between African American and Caucasian families. Because minority status was significantly associated with lower levels of PI, perhaps ethnic or minority status is better conceptualized as a risk factor of PI than as a moderator of the relationship between other risk factors and PI. Because of the site $\times$ ethnicity confound in this study, we were unable to include minority status as a risk factor in our path model and retain enough power to investigate its relations with the PI factors relative to the other risk factors.

Although there was no overall significant difference in the patterns of relations between African American and Caucasian families, there were substantial differences in the magnitudes of some of the individual path coefficients. These large differences suggest that the lack of an overall significant difference in ethnic group patterns may be a result of the small sample size. In this study, these large individual path coefficient differences tentatively indicated that parents' educational level was a significant risk 
factor for two types of PI for Caucasian parents, but was not significantly related to PI for African American parents. These preliminary findings suggest that educational level may have a different meaning for African Americans than for Caucasians. Perhaps, regardless of educational level, some African American parents may have had less positive school experiences of their own, do not see education as the key to future opportunity, and feel uncomfortable, if not resentful, interacting with their children's teachers (Colbert, 1991). Another hypothesis is that their "role construction" (Hoover-Dempsey \& Sandler, 1995) of parenting does not include being involved in the school.

Future research should investigate the processes and mechanisms that account for the association among these risk factors and PI. Hoover-Dempsey and Sandler (1995) urged the field to look at process variables that impact PI such as the parent's role construction, parental sense of efficacy for helping the child succeed in school, and general opportunities and demands for parental involvement presented by the school and the child. By testing models of mediation that incorporate measures of attitudes and behaviors, we can better understand the connection between family and demographic variables and PI in schools. Variables such as family attitudes towards the school, teacher attitudes and practices, parents' sense of selfefficacy in the school environment, time constraints, and other life stressors are some possible mediators. Determining which of these modifiable risk factors are hindering school involvement will further facilitate the development of appropriate interventions.

Similarly, teacher attitudes and practices have been shown to be highly influential in determining parents' level of involvement (Epstein, 1991). Determining the relative influence of the family and demographic risk factors on PI for environments with either low or high levels of teacher-initiated involvement strategies could provide more evidence to bolster the strength of public policy and local interventions aimed at increasing teacher training and school programs related to PI. In short, if teacher practices are relevant in determining the level of parents' involvement in schools, then schools and teachers could implement programs or policies that increase positive teacher-initiated contact.

Examining how different types of PI differentially impact student academic achievement and social development would be informative in designing interventions that target the types of partnerships that most effectively and efficiently influence child outcomes. On the one hand, some general guidelines can be adopted by whole school systems to improve parent-school partnerships such as adopting a more parent-friendly atmosphere in the school. However, individually implemented PI interventions must be flexible in order to be sensitive to context-specific issues related to the parent, the teacher, the child, and the school. There is much work to be done in the field of PI in schools. However, each step that we take will 
improve our understanding of the many factors that come into play in a complex multifaceted relationship such as the ones between schools and families. If this increased understanding is utilized to inform local intervention efforts and public policy, a real difference can be made in the futures of children, families, and schools.

\section{ACKNOWLEDGMENTS}

This work was supported by National Institute of Mental Health (NIMH) grants R18 MH48043, R18 MH50951, R18 MH50952, and R18 MH50953. The Center for Substance Abuse Prevention has also provided support for Fast Track through a memorandum of agreement with NIMH. This work was also supported, in part, by Department of Education grant S184U30002 and NIMH grants K05 MH00797 and K05 MH01027. We thank Jonathan Kanter for his helpful comments.

\section{REFERENCES}

Alexander, K. L., \& Entwisle, D. R. (1996). Schools and children at risk. In A. Booth \& J. F. Dunn (Eds.), Family school links: How do they affect educational outcomes? (pp. 67-88). Mahwah, NJ: Erlbaum.

Bierman, K. L. (1996). Family-school links: An overview. In A. Booth \& J. F. Dunn (Eds.), Family school links: How do they affect educational outcomes? (pp. 275-288). Mahwah, NJ: Erlbaum.

Colbert, R. D. (1991). Untapped resource: African American parental perception. Elementary School Guidance and Counseling, 26, 96-105.

Comer, J. P. (1988). Educating poor minority children. Scientific American, 259, 42-48.

Conduct Problems Prevention Research Group. (1992). A developmental and clinical model for the prevention of conduct disorder: The FAST Track Program. Development and Psychopathology, 4, 509-527.

Conduct Problems Prevention Research Group. (1995). Technical reports for the construct development for the measures for Year 2 outcome analyses. Unpublished technical report.

Coyne, J. C. (1976). Depression and the response of others. Journal of Abnormal Psychology, 85, 186-193.

Cummings, E. M., \& Davies, P. T. (1994). Maternal depression and child development. Journal of Child Psychology and Psychiatry, 35, 73-112.

Dauber, S. L., \& Epstein, J. L. (1989). Parents' attitudes and practices of involvement in innercity elementary and middle schools (CREMS Rep. No. 33). Baltimore: Johns Hopkins University, Center for Research on Elementary and Middle Schools.

Downey, G., \& Coyne, J. C. (1990). Children of depressed parents: An integrative review. Psychological Bulletin, 108, 50-76.

Dumas, J. E., \& Serketich, W. J. (1994). Maternal depressive symptomatology and child maladjustment: A comparison of three process models. Behavior Therapy, 25, 161-181.

Eccles, J. S., \& Harold, R. D. (1996). Family involvement in children's and adolescents' schooling. In A. Booth \& J. F. Dunn (Eds.), Family school links: How do they affect educational outcomes? (pp. 3-34). Mahwah, NJ: Erlbaum.

Epstein, J. L. (1984). Single parents and the schools: Effects of marital status on parent and teacher evaluation (Rep. No. 353). Baltimore: Johns Hopkins University, Center for Social Organization of Schools. 
Epstein, J. L. (1991). Effects on student achievement of teachers' practices of parent involvement. Advances in Reading/Language Research, 5, 261-276.

Epstein, J. L. (1995). School/family/community partnerships: Caring for the children we share. Phi Delta Kappan, (May), 701-712.

Epstein, J. L. (1996). Perspectives and previews on research and policy for school, family, and community partnerships. In A. Booth \& J. F. Dunn (Eds.), Family school links: How do they affect educational outcomes? (pp. 209-246). Mahwah, NJ: Erlbaum.

Greenberg, M. T., Lengua, L. J., Coie, J. D., Pinderhughes, E. E., \& Conduct Problems Prevention Research Group. (1999). Predicting developmental outcomes at school entry using a multiple-risk model: Four American communities. Developmental Psychology, 35, 403-417.

Griffith, J. (1996). Test of a model of the organizational antecedents of parent involvement and satisfaction with public education. Human Relations, 49, 1549-1571.

Grolnick, W. S., Benjet, C., Kurowski, C. O., \& Apostoleris, N. H. (1997). Predictors of parent involvement in children's schooling. Journal of Educational Psychology, 89, 538548.

Grolnick, W. S., \& Slowiaczek, M. L. (1994). Parents' involvement in children's schooling: A multidimensional conceptualization and motivational model. Child Development, 65, 237-252.

Haynes, N. M., Comer, J. P., \& Hamilton-Lee, M. (1989). School climate enhancement through parental involvement. Journal of School Psychology, 27, 87-90.

Henderson, A. T. (1987). The evidence continues to grow: Parent involvement improves student achievement. Columbia, MD: National Committee for Citizens in Education.

Hoover-Dempsey, K. V., Bassler, O. C., \& Brissie, J. S. (1992). Exploration in parentschool relations. Journal of Educational Research, 85, 287-294.

Hoover-Dempsey, K. V., \& Sandler, H. M. (1995). Parental involvement in children's education: Why does it make a difference? Teachers College Record, 97, 310-331.

Kellaghan, T., Sloane, K., Alvarez, B., \& Bloom, B. S. (1993). The home environment and school learning: Promoting parental involvement in the education of children. San Francisco: Jossey-Bass.

Kohl, G. K., Weissberg, R. P., Reynolds, A. J., \& Kasprow, W. J. (1994). Teacher perceptions of parent involvement in urban elementary schools: Sociodemographic and school adjustment correlates. Paper presented at the annual meeting of the American Psychological Association, Los Angeles, CA, August.

Lareau, A. (1996). Assessing parent involvement in schooling: Critical analysis. In A. Booth \& J. F. Dunn (Eds.), Family school links: How do they affect educational outcomes? (pp. 57-64). Mahwah, NJ: Erlbaum.

Leitch, M. L., \& Tangri, S. S. (1988). Barriers to home-school collaboration. Educational Horizons, 67, 70-74.

Lochman, J. E., \& Conduct Problems Prevention Research Group. (1995). Screening of child behavior problems for prevention programs at school entry. Journal of Consulting and Clinical Psychology, 63, 549-559.

Lynch, E. W., \& Stein, R. C. (1987). Parent participation by ethnicity: A comparison of Hispanic, Black, and Anglo families. Exceptional Children, 54, 105-111.

Moles, O. C. (1993). Collaboration between schools and disadvantaged parents: Obstacles and openings. In N. F. Chavkin (Ed.), Families and schools in a pluralistic society (pp. 21-49). Albany, NY: State University of New York Press.

Radloff, L. S. (1977). The CES-D Scale: A self-report depression scale for research in the general population. Applied Psychological Measurement, 1, 385-401.

Reynolds, A. J. (1992). Comparing measures of parent involvement and their effects on academic achievement. Early Childhood Research Quarterly, 7, 441-462. 
Reynolds, A. J., Weissberg, R. P., \& Kasprow, W. (1992). Prediction of early social and academic adjustment of children from the inner-city. American Journal of Community Psychology, 20, 599-624.

Seefeldt, C., Denton, K., Galper, A., \& Younoszai, T. (1998). Former Head Start parents' characteristics, perceptions of school climate, and involvement in their children's education. Elementary School Journal, 98, 339-349.

U.S. Department of Education. (1994). The Goals 2000: Educate America Act-Launching a new era in education. Washington, DC: Author.

U.S. Department of Education. (1996). Parents' report of school practices to involve families (NCES 97-327). Washington, DC: National Center for Education Statistics.

Watkins, T. J. (1997). Teacher communications, child achievement, and parent traits in parent involvement models. Journal of Educational Research, 91, 3-14.

Werthamer-Larsson, L., Kellam, S. G., \& Wheeler, L. (1991). Effect of first-grade classroom environment on shy behavior, aggressive behavior, and concentration problems. American Journal of Community Psychology, 19, 585-602.

Zill, N. (1996). Family change and student achievement: What we have learned, what it means for schools. In A. Booth \& J. F. Dunn (Eds.), Family school links: How do they affect educational outcomes? (pp. 139-174). Mahwah, NJ: Erlbaum. 